\title{
Glycoside rich fraction from Spondias pinnata bark ameliorate iron overload induced oxidative stress and hepatic damage in Swiss albino mice
}

\author{
Dipankar Chaudhuri, Nikhil Baban Ghate, Sourav Panja, Tapasree Basu, Anil Khushalrao Shendge \\ and Nripendranath Mandal*
}

\begin{abstract}
Background: Iron in the overloaded condition in liver promotes the overproduction of free radicals that lead to oxidative stress and ultimately hepatic damage. The present study was designed to evaluate the ameliorating potential from iron overloaded hepatotoxicity by the glycosidic fraction from Spondious pinnata bark (SPW1) along with its antioxidant property.

Methods: The fraction was tested for its in vitro antioxidant, free radical scavenging property and iron chelation potential via standard biochemical assays. Iron overload condition was generated by the intraperitoneal administration of iron dextran in mice. The levels of serum enzymes, antioxidant enzymes in liver, markers of hepatic damage, liver iron, and ferritin content were measured in response to the oral treatment of SPW1. Histopathology of the liver sections was performed for visual confirmation of the amelioration potential of SPW1.

Results: The fraction exhibited excellent in vitro antioxidant as well as free radical scavenging potential against both reactive oxygen species and reactive nitrogen species. Administration of SPW1 significantly normalized the disturbed levels of antioxidant enzymes, liver iron, lipid peroxidation, liver fibrosis, serum enzyme and ferritin better than standard desirox which were also supported by the morphological study of the liver sections. Phytochemical analysis as well as HPLC study, confirmed that the fraction mainly consisted of glycosidic phenolics and flavonoids that attributed to its biological activities.
\end{abstract}

Conclusions: The above results suggested that beneficial effects of SPW1 on iron overload induced hepatotoxicity that can be considered as a possible candidate against iron overload diseases.

Keywords: Antioxidant, Iron chelation, Histopathology, Phytochemicals, Hepatic damage, Serum enzymes

\section{Background}

Liver, the largest glandular organ in the body, plays a dynamic role in metabolism, biotransformation of proteins, carbohydrates, lipids and also detoxification of different endogenous and exogenous xenobiotics and drugs. Hence, the liver is liable to injury due to the chronic exposure to environmental toxicants, drugs and other xenobiotics [1]. Nowadays, iron overload mediated disorders like liver fibrosis, cirrhosis, inflammation,

\footnotetext{
* Correspondence: mandaln@rediffmail.com

Division of Molecular Medicine, Bose Institute, P 1/12, C. I. T. Road, Scheme VIIM, Kolkata 700054, West Bengal, India
}

diabetes, impaired cardiac function, arthritis and even cancer [2], are common throughout the world occurring mostly in major race/ethnic groups [3]. Moreover, iron overloaded toxicity caused a major problem in thalassemic patients than other type of liver toxicity. Although, iron, one of the most important redox metals, is essential for different cellular processes as there is a close relationship between iron essentiality and iron toxicity. Excess iron causes a serious damage to the liver that is the main storage site of iron in our body, by forming hydroxyl radical mediated oxidative stress. So, protection against metal toxicity by chelating metal ions or by 
trapping free radicals (antioxidant) is an effective lifesaving strategy for nearly all the iron overload-induced diseases mentioned above [4]. In addition to endogenous antioxidant systems, consumption of natural supplements that is rich in natural antioxidants also exhibits increased resistance to oxidative stress by altering the redox environment and is associated with a lower risk of many oxidative stress-related diseases.

Different phytochemicals mainly natural water soluble phenolics and flavonoids are used to treat iron-induced liver toxicity as they can efficiently scavenge most of the free radicals through their relevant iron chelating capabilities. From the previous publications, it was observed that $70 \%$ methanol extract of Spondias pinnata (Linn. f.) Kurz (Fam. Anacardiaceae) possessed both in vitro \& in vivo antioxidant and iron-chelating potential, which was supported by the presence of significant amounts of phenolics and flavonoids [5, 6]. These previous studies prompted us to separate the water soluble glycosidic compounds from S. pinnata bark and evaluate their ameliorating effect on iron overload-induced hepatotoxicity and hepatic fibrosis in mice.

\section{Methods}

\section{Reagents}

2,2'-azinobis-(3-ethylbenzothiazoline-6-sulfonic acid) (ABTS) was purchased from Roche diagnostics, Germany and 6-hydroxy-2,5,7,8-tetramethylchroman2-carboxylic acid (Trolox) was obtained from Fluka, Switzerland. Bathophenanthrolinesulfonate disodium salt, 5,5'-dithiobis-2-nitrobenzoic acid (DTNB) and N(1-Naphthyl) ethylenediaminedihydrochloride (NED) were procured from Sisco Research Laboratories Pvt. Ltd, India. 1-chloro-2,4-dinitrobenzene (CDNB), Dimethyl-4aminobenzaldehyde, and N,N- dimethyl-4-nitrosoaniline ammonium iron (II) sulfate hexahydrate $\left(\left(\mathrm{NH}_{4}\right)_{2} \mathrm{Fe}\left(\mathrm{SO}_{4}\right)_{2}\right.$, $6 \mathrm{H}_{2} \mathrm{O}$ ) were obtained from Merck, Mumbai, India. Guanidine hydrochloride and Iron-dextran was purchased from Sigma-Aldrich, USA. Desirox (Deferasirox) was obtained from Cipla Ltd., India. All of the other used reagents were of molecular biology grade and were obtained from reputable suppliers.

\section{Test animals}

In vivo experiments were performed abiding by the guidelines of the Committee for the Purpose of Control and Supervision of Experiments on Animals (CPCSEA), Ministry of Environment and Forest, Govt. of India with due approval from the Institutional Animal Ethics Committee, Bose Institute (Registration. No. 95/1999/ CPCSEA). Male Swiss albino mice $(20 \pm 2$ g) were obtained from the Chittaranjan National Cancer Institute (CNCI), Kolkata, India and were acclimated under a constant $12 \mathrm{~h}$ light / dark cycle at $22 \pm 2{ }^{\circ} \mathrm{C}$. The animals were fed general laboratory diet and water ad libitum. Experimental animals were taken care every six hour during the treatment period, and it was observed that there was no unwanted animal death. All surgeries were done using ethyl ether as an anesthetic, taking utmost care to reduce suffering.

\section{Plant material}

S. pinnata bark was collected from the villages of Bankura district, West Bengal, India and the plant was authenticated by Dr. Jayaram Hazra, Director, Central Research Institute of Ayurveda (CRIA), Kolkata, India. The herbarium was submitted at CRIA, Kolkata with an accession no of CRHS 111/08.

\section{Fractionation of crude extract}

The powdered S. pinnata stem bark was extracted with $70 \%$ methanol and water [5]. The lyophilized extract was re-extracted successively with hexane, chloroform, ethyl acetate and water. The water fraction again fractionated by acetylation $(2 \mathrm{ml}$ of pyridine and $2 \mathrm{ml}$ of acetic anhydride was stirred with $500 \mathrm{mg}$ of water fraction at $40{ }^{\circ} \mathrm{C}$ for $6 \mathrm{~h}$ ) followed by silica gel column chromatography purification (major spot) and deacetylation (150 mg of sodium methoxide was stirred with $500 \mathrm{mg}$ of acetylated product dissolved in $50 \%$ methanol in dichloromethane at room temperature for $6 \mathrm{~h}$ ) to get the fraction namely SPW1.

\section{In vitro study}

\section{Antioxidant potentials}

Antioxidant capacities of SPW1 was evaluated by $\mathrm{ABTS}^{*+}$ radical cation decolorization assay, DPPH (2,2-diphenyl-1-picrylhydrazyl) scavenging assay, and $\mathrm{Fe}^{3+}$-reducing power assay according to a standard method [5]. The scavenging percentage was quantified using test and control experiment values.

\section{Free radical scavenging activity}

In vitro reactive oxygen species (ROS) scavenging properties were determined by superoxide, hydroxyl, hypochlorous and singlet oxygen radical scavenging assays, and reactive nitrogen species (RNS) scavenging activity was determined by nitric oxide and peroxynitrite radical scavenging assays following standard procedures [5].

\section{In vitro iron chelation and ferritin iron release}

The $\mathrm{Fe}^{2+}$ chelating ability was determined as described earlier, and the result was expressed as inhibition percentage [5]. Iron reduction and release were determined using ferrozine, a spectrophotometric reagent for iron, as previously described [7]. Briefly, the reaction was initiated by adding different concentrations $(100-500 \mu \mathrm{g} /$ $\mathrm{ml}$ ) of test compounds in $50 \mathrm{mM}$ phosphate buffer 
(pH 7.0) containing $200 \mu \mathrm{g}$ ferritins and $500 \mu \mathrm{M}$ ferrozine, and the absorbance change was measured for $20 \mathrm{~min}$ at $560 \mathrm{~nm}$.

\section{In vivo study \\ Experimental design}

In total, six groups of mice were randomly prepared to consist of six mice per group. Among them, one group received normal saline only, which was labeled as a blank (B); however, other groups were intoxicated with five doses of $100 \mathrm{mg} / \mathrm{kg}$ b.w. iron-dextran (one dose every alternative day) by intraperitoneal injection (ip). Of the groups, one iron-dextran group (C) was treated orally with the only saline, and other groups were treated with $50 \mathrm{mg} / \mathrm{kg}$ b.w SPW1 (S50), $100 \mathrm{mg} / \mathrm{kg}$ b.w. SPW1 (S100), $200 \mathrm{mg} / \mathrm{kg}$ b.w. SPW1 (S200), test samples and $20 \mathrm{mg} / \mathrm{kg}$ b.w. desirox (D) for 21 consecutive days starting on the day following the first iron-dextran injection. The doses of SPW1 were selected on the basis of the obtained $\mathrm{LD}_{50}$ value $(1309 \mathrm{mg} / \mathrm{kg}$ b.w.). All experimental animals were sacrificed on the 22nd day under mild anesthesia (ethyl ether), and the cardiac puncture was performed to collect blood and serum was separated and stored at $-80{ }^{\circ} \mathrm{C}$. After collecting the blood, the liver was quickly excised, cleaned thoroughly with cold phosphate buffer saline (PBS) to remove the remaining blood and cut into three sections. The major liver portion was dissected and homogenized using 10 volumes of $0.1 \mathrm{M}$ phosphate buffer ( $\mathrm{pH}$ 7.4) supplemented with $0.15 \mathrm{M} \mathrm{NaCl}$ and $5 \mathrm{mM}$ EDTA and centrifuged for $30 \mathrm{~min}$ at $8000 \mathrm{~g}$ in the cold. The clear homogenate (supernatant) was collected and the protein concentration was quantified by the Folin-Lowry method, where BSA was used as a standard; the remaining supernatant was then stored at $-80{ }^{\circ} \mathrm{C}$. The second liver fragment was treated with a mixture of nitric acid and sulfuric acid (1:1) to analyze the iron content. The last portion was processed for histopathological examinations. This procedures were performed according to pervious method [6].

\section{Serum markers}

Aspartate aminotransferase (ASAT), alanine aminotransferase (ALAT), and bilirubin levels in serum were evaluated using commonly available kits from Merck, India. Similarly, alkaline phosphatase (ALP) levels were measured by a kit from Sentinel Diagnostics, Italy.

\section{Antioxidant enzymes}

Superoxide dismutase (SOD), catalase (CAT), glutathioneS-transferase (GST), and reduced glutathione (GSH) levels were measured using previously described methods [6].

\section{Evaluation of liver damage and fibrosis}

Thiobarbituric acid reactive substances (TBARS) quantities were measured to evaluate the levels of lipid peroxidation. Protein oxidation levels were resolved by estimating protein carbonyl contents. Collagen content, an important marker of liver fibrosis in each sample was determined by multiplying 7.69 to overall hydroxyproline content. These values were measured using previously described methods [6].

\section{Serum ferritin and liver iron levels}

Manufacturer's instructions were followed to quantify serum ferritin levels using an ELISA kit from Monobind Inc., USA. Liver iron content was quantified using a previously reported method [6]. Briefly, samples were mixed with bathophenanthroline sulfonate and incubated at $37{ }^{\circ} \mathrm{C}$ for $30 \mathrm{~min}$, and absorbance was recorded using a spectrophotometer at $535 \mathrm{~nm}$.

\section{Histopathological studies}

Excised liver samples were cleaned with saline and fixed for two days in $10 \%$ buffered neutral formalin. Sections (5 $\mu \mathrm{m}$ thick) were paraffin-embedded and stained with hematoxylin and eosin (morphological examination), Perls' Prussian blue dye (iron content) and Masson's trichrome stain (liver fibrosis). Stained sections were checked microscopically for histopathological changes.

\section{Phytochemical analysis}

The presence of phytochemicals was evaluated following different standard methods [8,9]. HPLC analysis was performed according to the previous method to identify the bioactive phytochemicals [10] present in SPW1.

\section{Statistical analysis}

All of the data were reported as the mean \pm SD of six measurements. Statistical analysis was performed using KyPlot version 2.0 beta 15 (32 bit) and Microsoft Excel 2010. The relationships between the groups were evaluated using a paired $t$-test, and a $p$ value of $<0.05$ was considered to be statistically significant.

\section{Results}

\section{Fractionation of extract}

The polarity based fractionation by different solvents revealed that the water fraction yielded more than $90 \%$ of the total extract, indicating the fact that the activity of the crude extract was mainly due to water soluble polar compounds. Further to regroup the probable glycosidic compounds in water fraction, it was acetylated to convert the polar acid groups into non-polar acetyl group. This process would facilitate the separation of the similar group of compounds through silica gel chromatography. The major spot, among the other several minor 
spots, was isolated by silica gel column chromatography and further deacetylated to remove the acetyl groups to revert the native free carboxylic acid groups of the compounds in that fraction.

\section{In vitro study}

\section{Antioxidant potentials}

The overall picture of the antioxidative ability of SPW1 was evaluated by $\mathrm{ABTS}^{*+}$ radical cation scavenging, $\mathrm{DPPH}$ radical scavenging and reducing power capacity assays. It was observed that SPW1 possessed excellent total antioxidant capacity that is almost similar to the standard Trolox (Fig. 1a). Similarly the fraction also strongly scavenge DPPH radical as well as reduce the $\mathrm{Fe}^{3+}$ to $\mathrm{Fe}^{2+}$ by donating an electron which also support the antioxidative capacity of SPW1 (Fig. 1b, c respectively). The TEAC and the $\mathrm{IC}_{50}$ values listed in Table 1.

\section{Free radical scavenging activity}

The free radicals scavenging activity of the fraction SPW1 against different ROS \& RNS was depicted in the Fig. 2, and the $\mathrm{IC}_{50}$ values were listed in Table 1. From the Fig. 2 it was clear that the fraction scavenged/inhibited different ROS, and RNS especially superoxide, hypochlorous acid, peroxynitrite radicals since the activity of the fraction was better than the standards (Fig. 2a, c, f respectively). On the other hand, SPW1 exhibited moderate activity against singlet oxygen and nitric oxide radicals (Fig. 2d, e respectively) but failed to scavenge hydroxyl radical (Fig. 2b).

\section{In vitro iron chelation and ferritin iron release}

Iron $\left(\mathrm{Fe}^{2+}\right)$ chelation capability of SPW1 was determined by hindering the development of violet colored $\mathrm{Fe}^{2+}$-ferrozine (Fig. 3a). At the highest tested concentration, SPW1 disrupted the complex color formation up to $68 \%$. From the Fig. 3b it was observed that SPW1 effectively released iron $\left(\mathrm{Fe}^{3+}\right)$ from ferritin dose-dependently and also displayed significant positive correlation $\left(R^{2}=0.8041\right)$ between the reducing power and (\%) the iron released from ferritin (Fig. 3c).

\section{In vivo study \\ Liver iron and serum ferritin levels}

The iron overload condition was measured directly by the amount of iron in the liver and indirectly by ferritin content in serum. Compared to the normal mice the iron content (686\%) and serum ferritin (143\%) was elevated due to iron overload but on treatment with SPW1 reverted the iron content as well as ferritin content almost to the levels of normal mice (Fig. 4a, b respectively) and the $\mathrm{EC}_{50}$ values were listed in Table 2.

\section{Serum markers}

Intoxication with iron in mice liver elevated the serum ALAT, ASAT, ALP and bilirubin that denoted hepatic injury. As per Table 3, the levels of serum markers gradually dropped dose-dependently at the individual level on treatment with SPW1 and the $\mathrm{EC}_{50}$ values were listed in Table 2.

\section{Antioxidant enzymes}

Iron in overloaded condition induced oxidative stress and reduced the levels of antioxidant enzymes. After the treatment with SPW1, the dropped levels of SOD (89 \%), Catalase (73\%), GST (72\%), GSH (37\%) were dose-dependently restored nearly to the normal condition (Fig. 5a, b, c, d respectively) and the $\mathrm{EC}_{50}$ values were listed in Table 2. The effect of restoring the antioxidant enzymes level by SPW1 is better than desirox.

\section{Evaluation of liver damage and fibrosis}

The effect of iron overload on liver damage was measured by the level of lipid peroxidation, protein carbonyl and collagen content in the liver homogenate. The increased levels of these liver damage and fibrosis markers were reduced after oral administration of SPW1 (Fig. 6a, $\mathrm{b}, \mathrm{c}$ respectively) and the $\mathrm{EC}_{50}$ values were listed in Table 2.
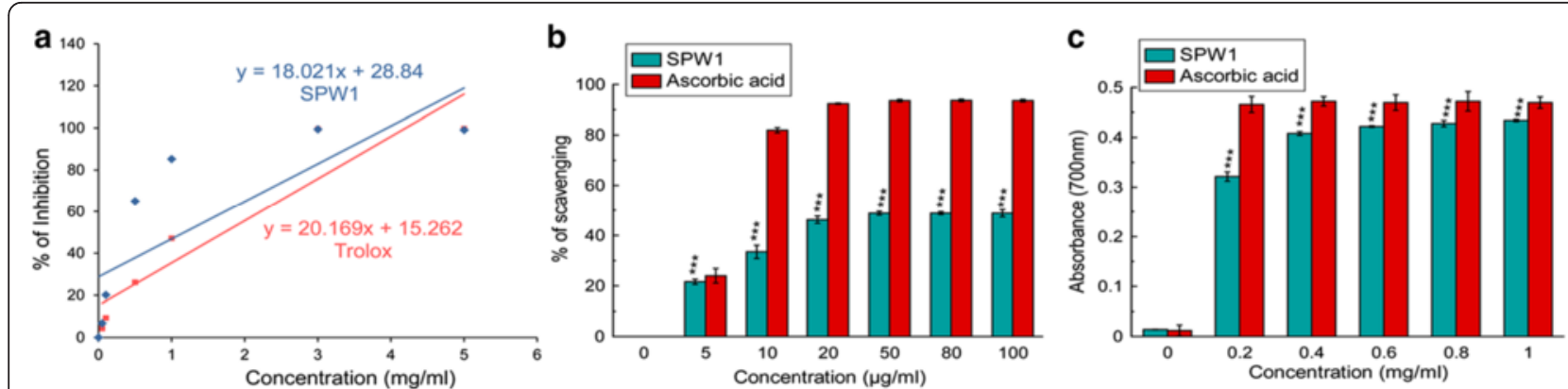

Fig. 1 Antioxidant potentials of SPW1. a Total antioxidant assay, b DPPH radical scavenging assay, $\mathbf{c}$ Reducing power assay. The results represent the mean \pm S.D. $(n=6) .{ }^{* *} p<0.001$ vs. control 
Table $1 I_{50}$ values of the SPW1 and standard compounds for different antioxidant, free radical and metal chelation assays

\begin{tabular}{lccc}
\hline Name of assay & SPW1 & Standards & Values of standard compounds \\
\hline DPPH & $50.76 \pm 1.49$ & Ascorbic acid & $5.29 \pm 0.28$ \\
Superoxide anion $\left(\mathrm{O}_{2} \cdot{ }^{-}\right.$) scavenging & $8.95 \pm 0.29$ & Quercetin & $42.06 \pm 1.35$ \\
Hydroxyl radical $(\mathrm{OH} \cdot)$ scavenging & $7244.91 \pm 905.97$ & Mannitol & $571.45 \pm 20.12$ \\
Hypochlorous acid $(\mathrm{HOCl})$ scavenging & $66.05 \pm 1.92$ & Ascorbic acid & $235.96 \pm 5.75$ \\
Singlet oxygen $\left({ }^{1} \mathrm{O}_{2}\right)$ scavenging & $202.81 \pm 7.95$ & Lipoic acid & $46.15 \pm 1.16$ \\
Nitric oxide radical $(\mathrm{NO})$ scavenging & $121.55 \pm 5.01$ & Curcumin & $90.82 \pm 4.75$ \\
Peroxynitrite $(\mathrm{ONOO}-)$ scavenging & $403.17 \pm 8.01$ & Gallic acid & $876.24 \pm 56.96$ \\
Iron chelating activity & $59.98 \pm 0.67$ & EDTA & $1.27 \pm 0.05$ \\
\hline
\end{tabular}

All the values are expressed in $\mu \mathrm{g} / \mathrm{ml}$. Data expressed as mean \pm S.D $(n=6)$. EDTA represents Ethylenediamine tetraacetic acid

\section{Histopathological studies}

Liver sections stained with hematoxylin and eosin from normal mice demonstrated normal cell morphology with prominent nuclei in the well-preserved cytoplasm and prominent central vein without cellular infiltration (Fig. 7a). Whereas iron dextran overloaded mice demonstrated various degrees of pathological changes including ballooning degeneration, inflammation, loss of cellular boundaries and hepatocellular necrosis (Fig. 7b). In contrast, SPW1 treated mice groups displayed attenuation of pathogenicity and gradual reversal to normal cytoarchitecture, thus restoring the normal condition (Fig. 7c, $\mathrm{d}$, e respectively). Figure $7 \mathrm{f}$ represents liver sections of the desirox-treated group with improved histology, which is similar to the highest dose of SPW1. Another detrimental effect of excess iron in the liver is deposition of iron in the form of crystalline ferritins and amorphous hemosiderin. Iron released from denatured ferritin, ferric oxide (unused iron) as well as broken hemoglobin formed a complex to store the iron known as hemosiderin. Perls' Prussian blue is commonly used to detect its deposition in liver tissue as blue patches. The liver sections from untreated iron overloaded mice demonstrated increased hemosiderin deposition (Fig. 8b) compared to normal mice (Fig. 8a). However, sections from the treated mice groups demonstrated a gradual decrease in hemosiderin deposition patches (Fig. 8c, d, e respectively). The highest treatment dose exhibited a parallel effect to the standard desirox-treated group (Fig. 8f). Accumulated collagen in liver was also stained blue using Masson's trichrome. The microscopic observation suggested that the liver section of control mice revealed normal lobular architecture and distribution of collagen (Fig. 9a). From the liver section of iron-overloaded mice,
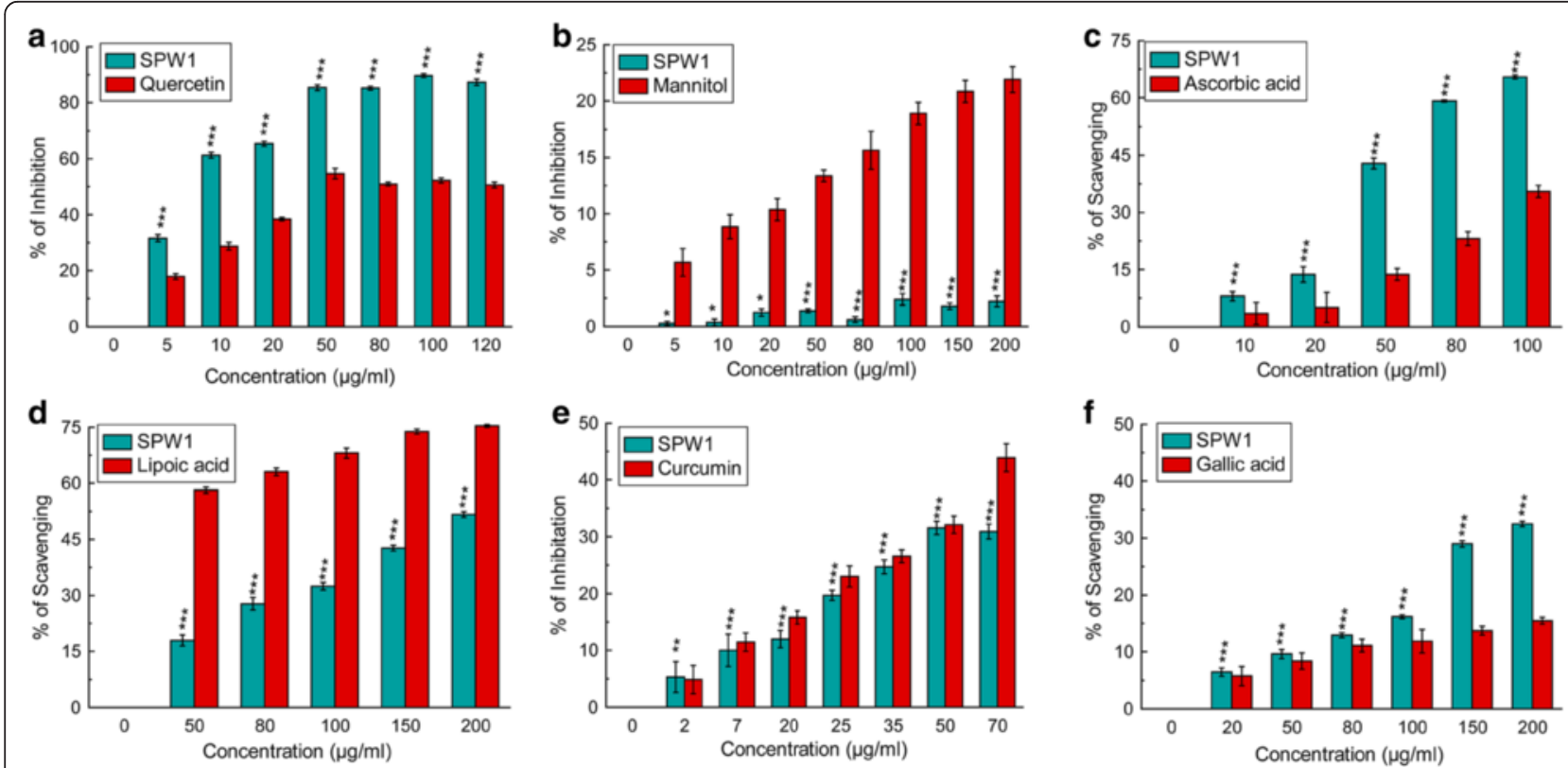

Fig. 2 ROS and RNS scavenging capabilities of SPW1. a Superoxide radical inhibition, b Hydroxyl radical inhibition, c Hypochlorous radical scavenging, $\mathbf{d}$ Singlet oxygen radical scavenging, e Nitric oxide inhibition, $\mathbf{f}$ Peroxynitrite radical scavenging. The results represent the mean \pm S.D. $(n=6) .{ }^{*} p<0.05,{ }^{* *} p<0.01$ and ${ }^{* * *} p<0.001$ vs. control 

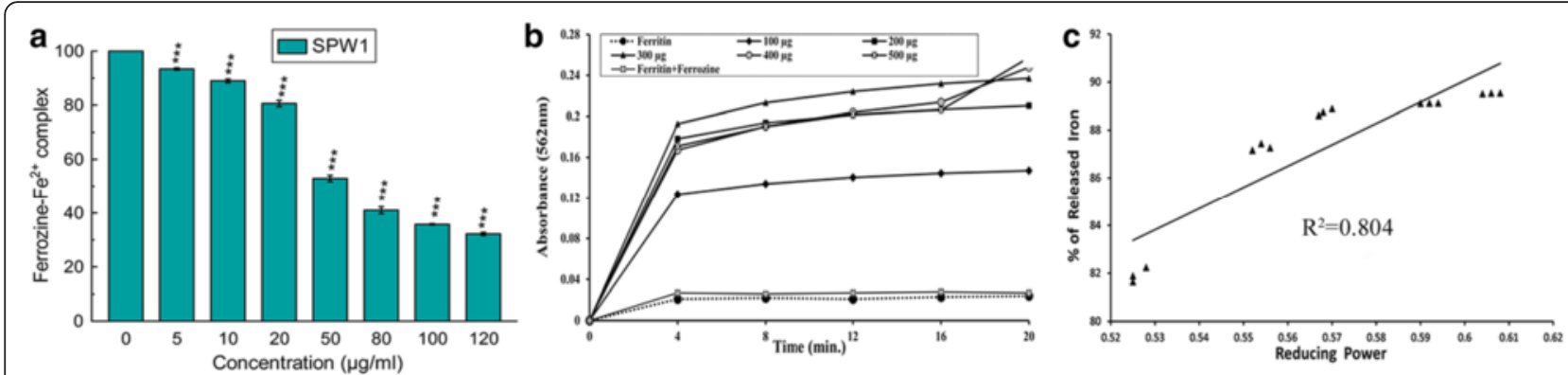

Fig. 3 In vitro iron chelation and reductive release of ferritin iron $\left(\mathrm{Fe}^{3+}\right)$. a Iron chelation activity $\mathbf{b}$ Iron release from ferritin c Correlation between iron released from ferritin with reducing power

it was evident that the normal architecture of the liver was destroyed and the nodules surrounded by accumulated collagen indicating fibrous cirrhotic (Fig. 9b). However, after treatment with SPW1, a gradual decrease in the degree of collagen deposition was observed (Fig. 9c, $\mathrm{d}$, e respectively). Here also, the treatment with the highest dose demonstrated a similar scenario when compared to the standard desirox-treated group (Fig. 9f).

\section{Phytochemical analysis}

Qualitative determination of the phytochemicals ensured the presence of phenolics, flavonoids, carbohydrates, tannins, glycosides and terpenoids (Table 4). However, quantitative analysis revealed that phenolics and glycosides dominated over the other phytochemicals tested (Table 4). HPLC analysis was done to identify the probable bioactive compounds comparing the retention time of the standard compounds. Major peaks with retention time $3.5,6.1,50.12,67.11 \mathrm{~min}$ appear on the HPLC chromatogram. Among them, two peaks were identified as tannic acid (3.5 min) and rutin (67.11 $\mathrm{min})$ and other peaks were remained unidentified (Fig. 10).

\section{Discussion}

Iron, one of the essential metals needed in our animal kingdom, acts as the most common cofactor within the oxygen handling biological machinery. However, iron in excess, induced the overproduction of various free radicals which is not always effectively normalized by the internal antioxidant defense machinery caused oxidative stress related complications [11]. As our body lacks the mechanism to transmute excess iron into any other substance, the only way to stop the detrimental effect of free or partially liganded 'iron' is to make sure that all of its six possible ligands are satisfied, whether by endogenous chelators or those added from the diet or as pharmaceuticals [12]. The ability of the antioxidant cum iron chelating agent to reduce the toxic effect or restore the normal physiological condition is the index of its hepato-ameliorating potential, which was noticeably attained by the treatment with SPW1 in this present study.

The antioxidant capacity of SPW1 was evaluated by the decolourization of the ABTS.$^{+}$and reducing property of $\mathrm{Fe}^{3+}$ along with the scavenging property of $\mathrm{DPPH}$, stable free radicals. The assays produced an
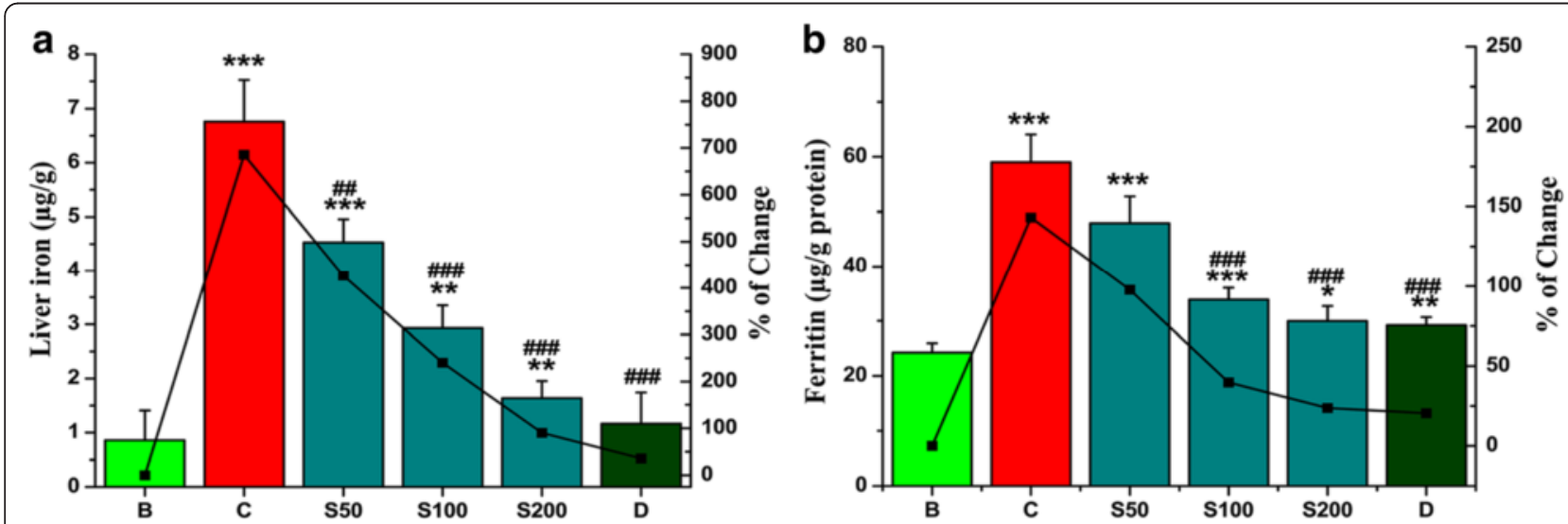

Fig. 4 Removal of overloaded iron from mice liver and blood serum. a Iron load in liver cell, $\mathbf{b}$ Level of ferritin in serum. Mouse groups (B, C, S50, $\mathrm{S} 100, \mathrm{~S} 200, \mathrm{D})$ were treated as described in the 'Experimental design' section. Values are expressed as the mean \pm SD of six mice. ${ }^{*} p<0.05$, ${ }^{* *} p \leq 0.01,{ }^{* *} p \leq 0.001$ compared with the blank and ${ }^{\#} p<0.05,{ }^{\# \#} p<0.01,{ }^{\# \#} p \leq 0.001$ compared with the control 
Table 2 EC $_{50}$ values of SPW1 in deferent assays

\begin{tabular}{ll}
\hline Name of the assays & $\mathrm{EC}_{50}$ of SPW1 (mg/kg.b.w.) \\
\hline Serum ferritin and liver iron levels & $177.491 \pm 8.80$ \\
Serum Ferritin & $81.15 \pm 11.57$ \\
Liver Iron & \\
Serum Markers & $73.77 \pm 4.19$ \\
ALAT & $140.01 \pm 16.99$ \\
ASAT & $159.32 \pm 8.79$ \\
ALP & $263.18 \pm 15.65$ \\
Bilirubin & \\
Antioxidant enzymes & $27.99 \pm 11.90$ \\
SOD & $84.29 \pm 11.27$ \\
Catalase & $90.84 \pm 10.92$ \\
GST & $389.19 \pm 25.68$ \\
GSH & \\
Liver damage parameter & $223.10 \pm 8.65$ \\
Lipid peroxidation content & $171.04 \pm 11.40$ \\
Protein carbonyl content & $205.59 \pm 7.26$ \\
Collagen content & \\
\hline
\end{tabular}

overall picture of the antioxidative property of the fraction as the total antioxidant assay, and the reducing power is complimentary to each other. The excellent DPPH radical scavenging power of the fraction gives an initial idea about the radical scavenging property.

Different ROS such as superoxide, hydroxyl and singlet oxygen radicals induced several damages to different biomolecules. Especially, superoxide radical is known as an initiator to generate other free radicals such as hydrogen peroxide or singlet oxygen in the living system [13]. Hydroxyl radicals react with the lipid membrane and produce proxy and alkoxy radical which in turn initiate the chain reaction [14]. On the other hand RNS like nitric oxide in excess causes various inflammatory diseases and when it reacts with superoxide radical it produces more toxic peroxynitrite radical that directly damages different tissues [5, 15]. From the Fig. 2, it is clear that SPW1 acted as a free radical scavenger, which effectively reduces the toxic effect of superoxide radical that in turn neutralized the threat by different ROS and RNS. Further, the radical scavenging property was supported by the in vitro iron chelation property (Fig. 3a) of the fraction as iron plays a crucial role in the generation of the free radicals.

This excellent in vitro antioxidant, free radical scavenging and iron chelation activity of the fraction leads us to test the sample for it's in vivo iron chelation as well as hepato-ameliorating activity in Swiss albino mice. Several previous studies suggest that iron in excess, induced hepatic damage as the liver is the main storage site for iron in our body [16]. To screen the hepatoprotective potential, intraperitoneal iron-dextran injection followed by oral treatment is a reliable method. Desirox (Generic name-Deferasirox) used as positive control because it binds to iron with high affinity in a 2:1 ratio with its tridentate ligand. A study by Cheong et al. [17] showed that Deferasirox is effective in reducing serum-ferritin and liver iron concentration level in transfusional iron overload patients. In addition, it also positively recovers hematologic and hepatic function.

The leftover iron in our body is stored in the hepatic cells as ferritin or hemosiderin [18]. Thus, measurement of the iron levels in liver is used for diagnosis the ironload in iron overloaded disease. In contrast, ferritin, a ubiquitous intracellular iron-binding protein in serum, generally stores iron in a non-toxic ferric form and releases it in a controlled fashion whenever needed [19]. So a level of serum ferritin is an indirect key marker revealing the amount of hepatic iron content. The highest dose of SPW1 significantly eliminated the surplus iron justify its iron chelation property. On the other hand, to overcome iron overloaded state, various readily available iron chelator drugs were administered, but many of them struggle with a narrow binding capacity for ferric iron $\left(\mathrm{Fe}^{3+}\right)$. The Fig. 3b signified that increasing concentrations of SPW1 significantly released iron $\left(\mathrm{Fe}^{3+}\right)$ from ferritin with time and the correlation between the percentage of iron released from ferritin and the reducing power (Fig. 3c) was quite significant $\left(R^{2}=0.804\right)$. This

Table 3 The changes in ALAT, ASAT, ALP and Bilirubin levels after oral therapy with SPW1

\begin{tabular}{|c|c|c|c|c|c|c|c|c|}
\hline \multirow[t]{2}{*}{ Treatment } & \multicolumn{2}{|l|}{ ALAT } & \multicolumn{2}{|l|}{ ASAT } & \multicolumn{2}{|l|}{ ALP } & \multicolumn{2}{|l|}{ Bilirubin } \\
\hline & Unit/L & $\%$ change & $\overline{U n i t / L}$ & $\%$ change & Unit/L & $\%$ change & $\mathrm{mg} / \mathrm{dl}$ & $\%$ change \\
\hline B & $14.42 \pm 1.91$ & & $62.46 \pm 6.32$ & & $84.62 \pm 3.48$ & & $1.58 \pm 0.10$ & \\
\hline C & $64.60 \pm 0.73^{\times 3}$ & 347.88 & $234.91 \pm 8.30^{\times 3}$ & 276.13 & $252.63 \pm 4.92^{\times 3}$ & 198.56 & $3.15 \pm 0.18^{\times 3}$ & 99.67 \\
\hline S50 & $36.19 \pm 1.16^{\times 3 \times 3}$ & 150.91 & $170.49 \pm 12.54 \times 3 \times 3$ & 172.97 & $181.71 \pm 6.18^{\times 3 Y 3}$ & 114.74 & $2.42 \pm 0.25^{\times 2 Y 2}$ & 53.43 \\
\hline S100 & $27.47 \pm 1.55^{\times 3 \times 3}$ & 90.45 & $137.29 \pm 17.82^{\times 3 \curlyvee 3}$ & 119.82 & $149.48 \pm 7.02^{\times 3 Y 3}$ & 76.66 & $2.18 \pm 0.12^{\times 3 Y 3}$ & 38.41 \\
\hline S200 & $20.11 \pm 0.16^{\times 2 \times 3}$ & 39.41 & $97.62 \pm 8.16^{\times 3 \times 3}$ & 56.31 & $125.08 \pm 5.93 \times 3 Y 3$ & 47.81 & $1.99 \pm 0.13^{\times 3 Y 3}$ & 26.22 \\
\hline D & $19.85 \pm 0.79^{\times 3 Y 3}$ & 37.59 & $88.06 \pm 10.37^{\times 2 Y 3}$ & 40.99 & $114.97 \pm 6.13^{\times 3 \times 3}$ & 35.87 & $1.72 \pm 0.14^{\times 1 Y 3}$ & 8.92 \\
\hline
\end{tabular}

Mouse groups ( $\mathrm{B} ; \mathrm{C} ; \mathrm{S} 50, \mathrm{~S} 100, \mathrm{~S} 200, \mathrm{D})$ were treated as described in 'Experimental design' section. Values are mean $\pm \mathrm{SD}(n=6)$. X1: $p<0.05, X 2: p<0.01$ and X3: $p<0.001$ significant difference from $\mathrm{B}$ group. $\mathrm{Y} 1: p<0.05, \mathrm{Y} 2: p<0.01$ and $\mathrm{Y} 3: p<0.001$ significant difference from $\mathrm{C}$ group 

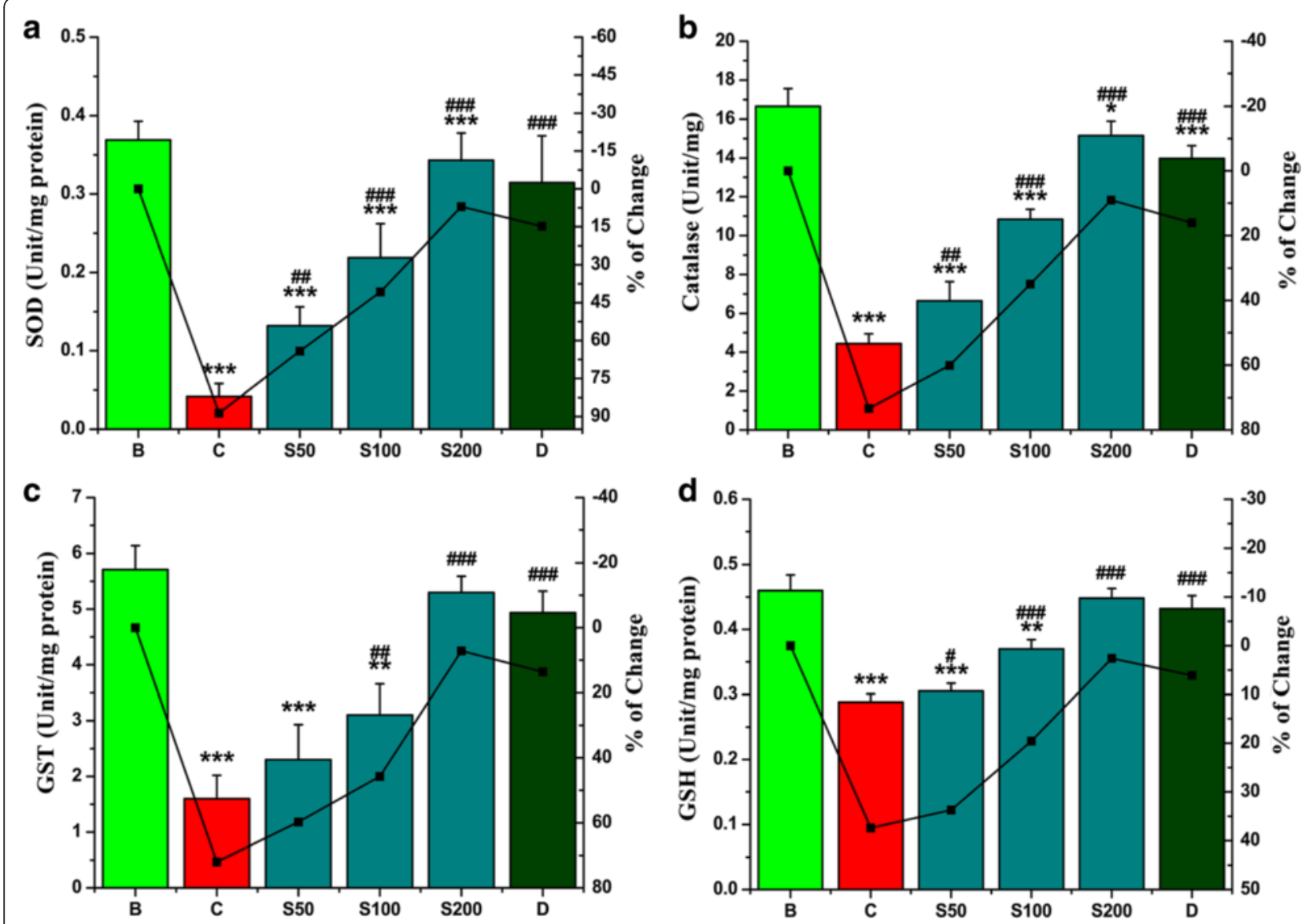

Fig. 5 Restoration of liver antioxidant enzyme levels after treatment with SPW1. a SOD, b Catalase, c GST, d GSH. Mouse groups (B, C, S50, S100, $\mathrm{S} 200, \mathrm{D})$ were treated as described in the 'Experimental design' section. Values are expressed as the mean $\pm \mathrm{SD}(n=6) .{ }^{*} p<0.05,{ }^{* *} p \leq 0.01$, ${ }^{* * *} p \leq 0.001$ compared with the blank and ${ }^{\#} p<0.05,{ }^{\# \#} p \leq 0.01$, \#\#\# $\mathrm{p} \leq 0.001$ compared with the control

result also validates that SPW1 alone effectively chelate the excess iron by reducing it from its ferric form.

Levels of serum enzyme are checked in the clinical diagnosis to determine the condition of various diseases and tissue injury $[20,21]$. As these enzymes are predominantly found in the hepatic cell, liver damage due to excess iron leads to the release of these intracellular enzymes into the blood [22] as evident by increased serum parameters (Table 3). The administration of SPW1 has reduced the increased level of the serum marker enzymes almost similar to the standard desirox. This result indicated towards its healing capabilities of hepatic parenchyma and regeneration of hepatocyte as well as its functional efficiency [23].
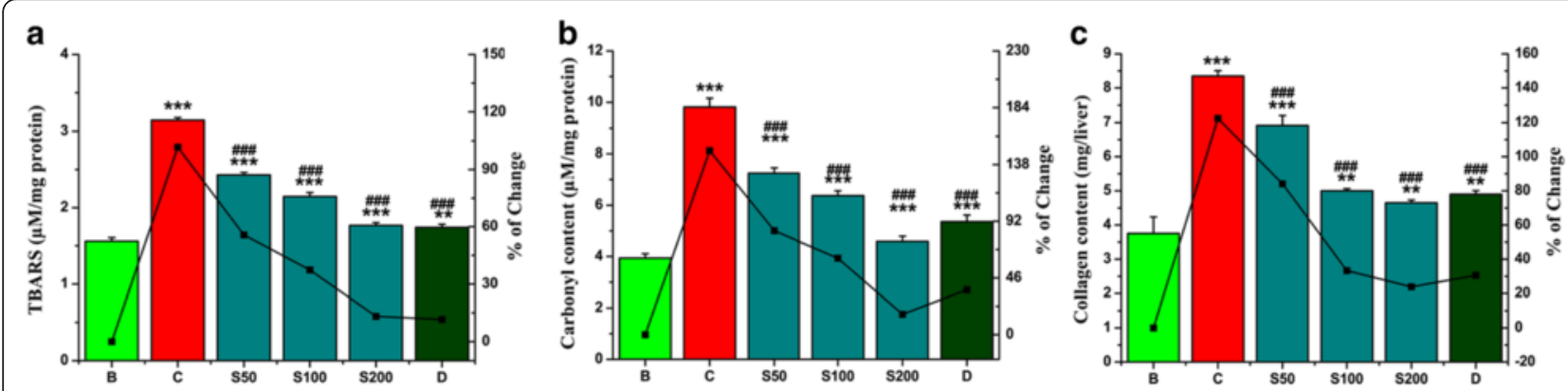

Fig. 6 SPW1 treatment gradually reduced the elevated levels of liver damage parameters. a Lipid peroxidation levels, b Protein carbonyl content, c Collagen content. Mouse groups (B, C, S50, S100, S200, D) were treated as described in 'Experimental design' section. Values are expressed as the mean $\pm \mathrm{SD}(n=6)$. ${ }^{* *} p \leq 0.01,{ }^{* * *} p \leq 0.001$ compared with the blank and ${ }^{\# \# \#} p \leq 0.001$ compared with the control 

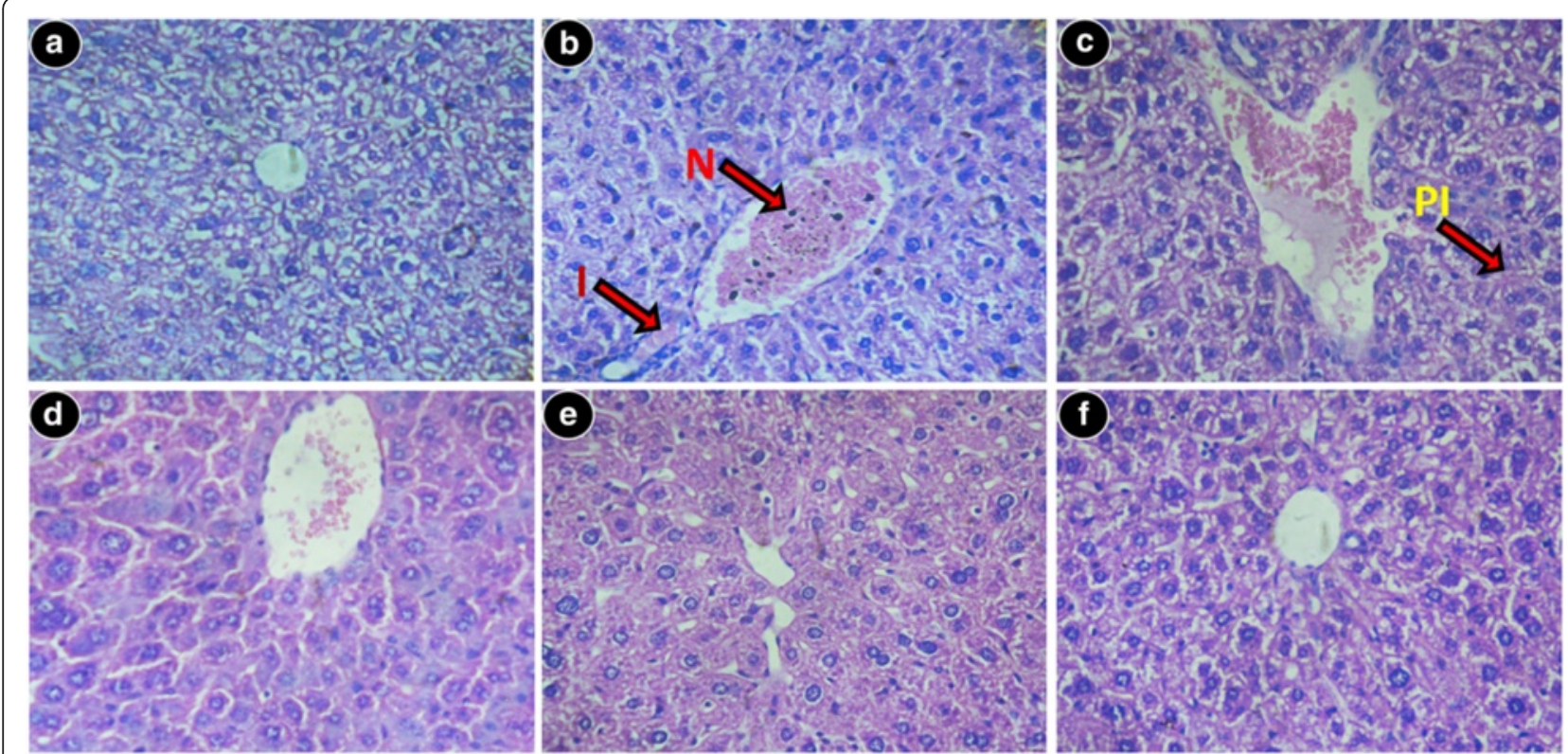

Fig. 7 Morphological evaluation of liver sections, stained with hematoxylin and eosin at $\times 400$. a Control mice liver with normal cyto-structure. $\mathbf{b}$ Iron-overloaded liver section showed disrupted cell membrane, inflammation ( () , and necrosis $(N)$. c Liver section from the S50 group showed improved histology with portal inflammation (P/). d Liver section from the S100 group. e Liver section from the S200 mouse group. $\mathbf{f}$ Cellular morphology is almost similar to Desirox-treated liver sections

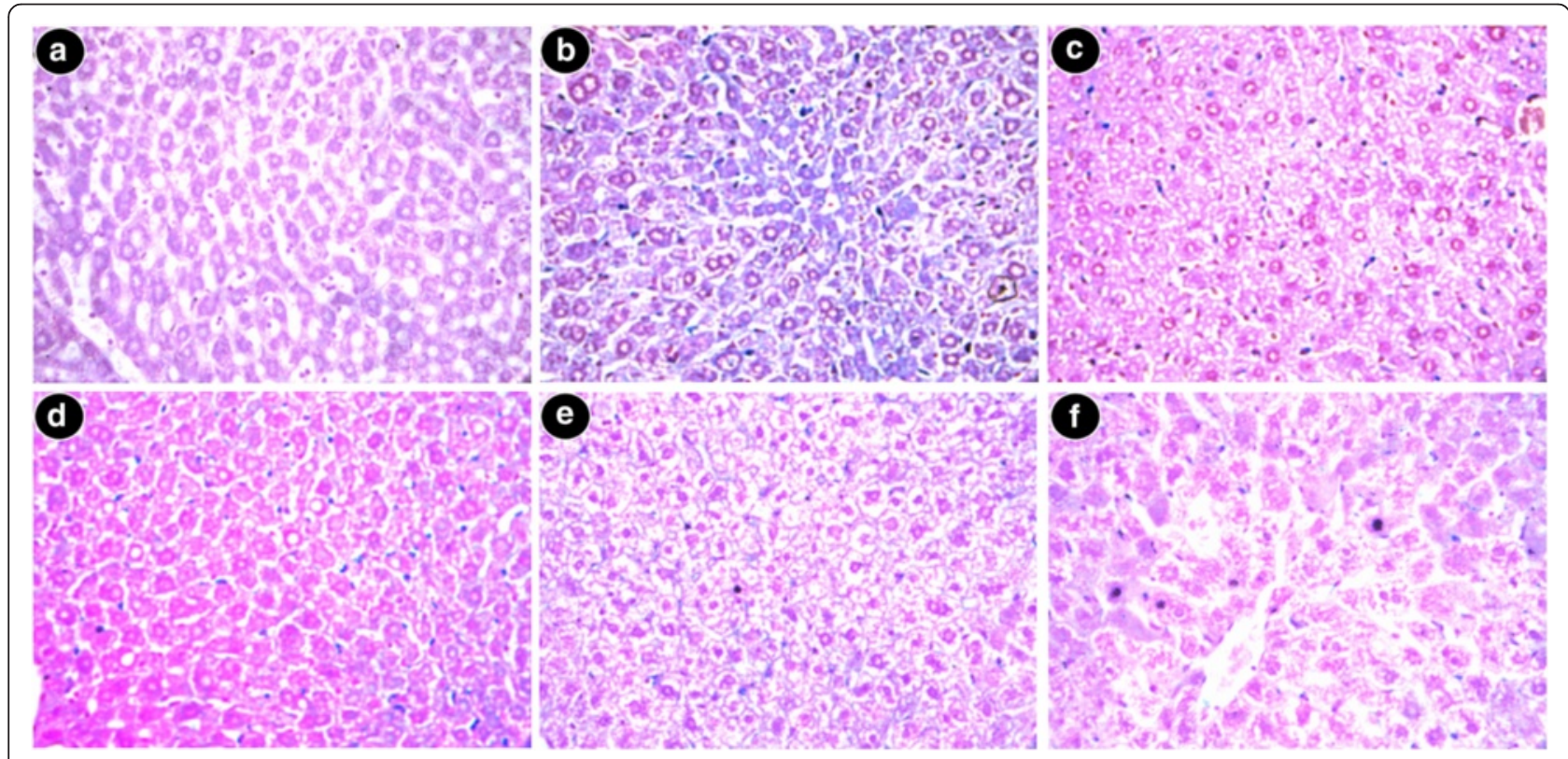

Fig. 8 Visual confirmation of iron removal potential of SPW1 by liver sections stained with Perls' Prussian blue at $\times 400$. a Control mice with minimal hemosiderin deposition patches (very low). $\mathbf{b}$ Excess blue patches denote iron-overloaded condition in mice. $\mathbf{c}$ Liver section from S50 mouse group. $\mathbf{d}$ Liver section from S100 mouse group e Liver section from S200 mouse group. All three groups (C, D, E) showed gradual reduction of the blue patches. $\mathbf{f}$ Desirox-treated liver section with lesser blue patches 


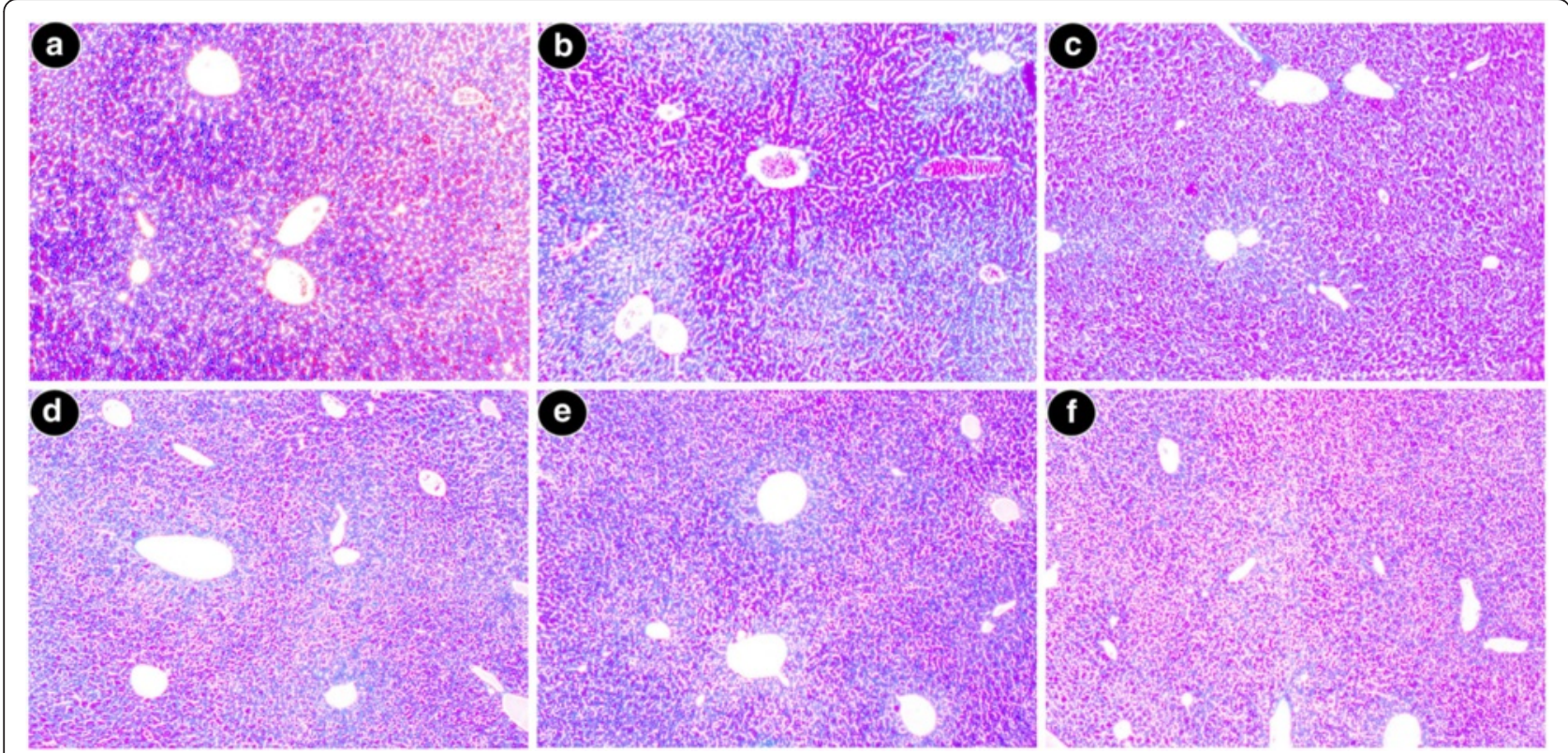

Fig. 9 Reduction of liver fibrosis observed by staining the liver sections with Masson's Trichrome $\times 100$. a Control mice showed no sign of fibrosis. b Iron-intoxicated mice displayed elongated fibrous septa and collagen accumulation (blue). c Liver section from S50 with lesser blue patches, d Liver section from S100 group e S200 demonstrates a nearly negligible collagen accumulation and healthy liver. $\mathbf{f}$ Desirox-treated liver section

To combat with the excess free radicals, living cells are armed with a group of intracellular antioxidant enzymes such as GST, SOD, CAT and the small compound GSH, which act as a first line of defenses. So estimation of the levels of these antioxidant enzymes is a proper indirect way to assess pro-oxidant-antioxidant combat in tissues [24]. Iron-overloaded condition stimulates the oxidative stress followed by the reduction of the levels of antioxidant enzymes. Oral treatments significantly restore the levels of the entire antioxidant enzymes to normal more readily than used drug desirox. This result signified the fraction SPW1 as a potent antioxidant agent both in vitro as well as in vivo condition.

The iron-overloaded condition increases the disease related serum enzymes and reduces the activity of cells antioxidant defense machinery, ultimately leading to liver tissue damage. The lipid bilayer is destroyed by hydroxyl radical (lipid peroxidation) and results to end products such as malondialdehyde (MDA) which in turn activate the stellate cells to initiate liver fibrosis [25-27]. After liver injury, the production of collagen predominates over hepatocellular regeneration as an immediate healing response, thereby occupying the injured areas instead of destroyed hepatocytes. Collagen content is therefore considered to be a major marker of liver fibrosis and hepatotoxicity [28]. Iron-induced liver pathogenicity also leads to the oxidation of various important structural and functional proteins and forms protein carbonyls. Thus, it serves as a marker of oxidative stress and leads to the onset/development of various diseases including cystic fibrosis and ulcerative colitis [29]. The chelation of excess iron by SPW1 subsequently reduced the liver damage and liver fibrosis indicating its hepato-ameliorating potency as shown in Fig. 6 which is again better than desirox.

Above all, liver biopsy is the ultimate standard to determine the degree of tissue damage and fibrosis alongside other pathological tests. The live sections stained with hematoxylin and eosin exhibited various degrees of

Table 4 Phytochemical analysis of SPW1

\begin{tabular}{|c|c|c|c|c|c|c|c|c|c|c|c|}
\hline \multirow[t]{2}{*}{ Sample } & \multirow[t]{2}{*}{ Tests } & \multicolumn{10}{|c|}{ Phytochemicals } \\
\hline & & Phenol & Flavonoid & Tannin & Carbohydrate & Glycoside & Alkaloid & Anthra & Sap & Terpen & Triterpen \\
\hline \multirow[t]{2}{*}{ SPW1 } & Qualitative & + & + & + & + & + & - & - & - & + & - \\
\hline & Quantitative & $44.23 \pm 1.08$ & $16.65 \pm 0.26$ & $6.36 \pm 0.06$ & $10.96 \pm 0.14$ & $31.48 \pm 0.09$ & ND & ND & ND & ND & ND \\
\hline
\end{tabular}

Anthra- Anthraquinone, Sap-Saponin, Terpen-Terpenoids, Triterpen- Triterpenoids. Total phenolics (mg/100 mg extract gallic acid equivalent), Total flavonoids (mg/100 mg extract quercetin equivalent), Tannin (mg/100 mg extract catechin equivalent), Carbohydtrate (mg/100 mg extract glucose equivalent), Glycoside (mg/100 mg extract Rutin equivalent), " + " represents presence of the phytoconstituent; "-" represents absence of the phytoconstituent. "ND" represents Not Determined 


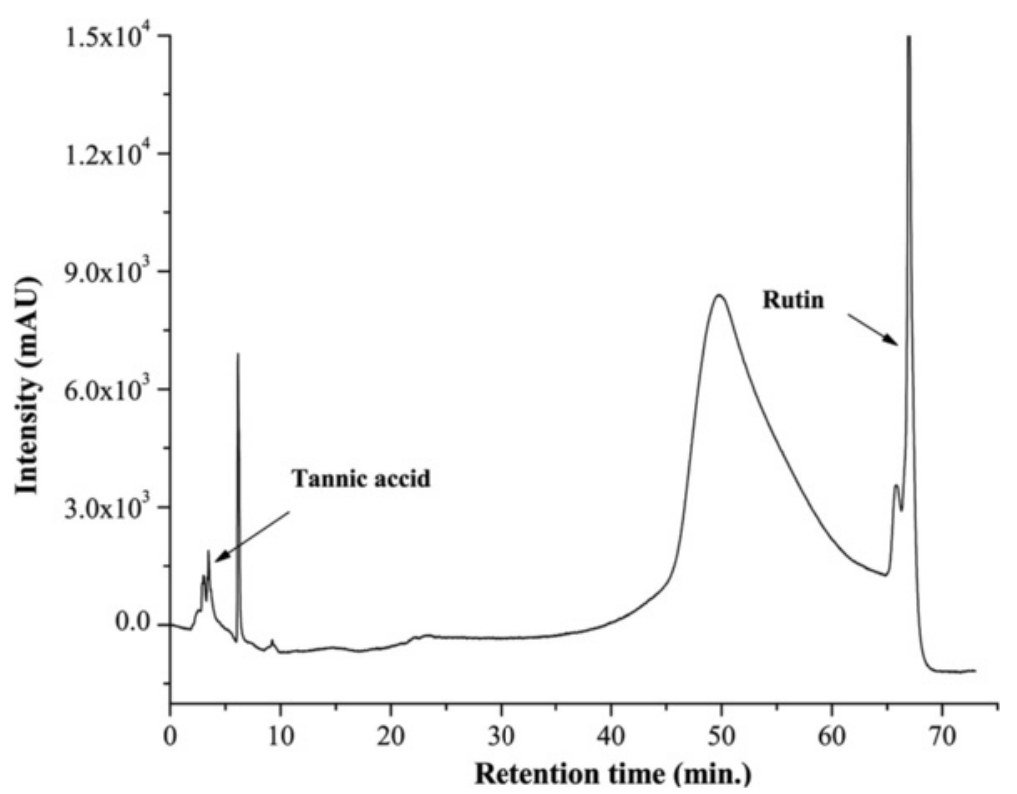

Fig. 10 HPLC analysis of SPW1. The marked peaks denote the retention of peaks matched with the retention of the respective standard phytochemicals in the same condition

inflammation, necrosis as well as cell wall degeneration in iron overloaded condition, but treatment with SPW1 reduced the tissue damage that also supported the result of the restoration of serum enzyme and antioxidant enzyme levels. Perls' Prussian blue staining revealed the visual confirmation of iron chelation property of the test sample along with the liver iron content and serum ferritin content. On the other hand, Masson's trichrome staining disclosed the reduction of liver fibrosis as the collagen content gradually decreased with the increasing doses of SPW1, which also confirmed the anti-fibrotic effect of the fraction along with the test for collagen content.

The presence of different phytochemicals confirmed the backbone of the bioactivity of SPW1. The adequate amounts of phenolic and glycosides in SPW1 revealed that the fractionation procedure mainly concentrated the glycosidic phenolics and flavonoids from the water fraction. This observation was also confirmed by the HPLC analysis, where only two compounds were identified, one of them is tannic acid (phenolic) and other is rutin (glycoside) and the major peak at $50.12 \mathrm{~min}$ is probably the combined peak of the other glycoside compounds. Literature survey revealed that, tannic acid, rutin and other glycosides are potent antioxidants, metal chelators thereby inhibiting lipid peroxidation, which also support their hepato-ameliorating potentials [30, 31]. Especially, rutin, a flavonoid glycoside, is found in wide variety of plants exhibit powerful anti-inflammatory activity along with its antioxidant, metal chelation and protective effects on hepatotoxicity [32].

\section{Conclusions}

From the present study, it could be concluded that SPW1 can be used as a favorable candidate to cure iron overload-mediated oxidative stress and hepatotoxicity as it is capable of both scavenging the free radicals and chelate the excess iron in the body. It also further concluded that the activity of SPW1 is mainly due to the glycosidic phenolic and flavonoid compounds present in it. Though, further studies are warranted to determine the exact mechanism(s) involved in the hepatoprotective activity of the SPW1 along with the complete characterization of all bioactive compounds present in this fraction.

\section{Abbreviations}

ALAT, alanine aminotransferase; ALP, alkaline phosphatase; ASAT, aspartate aminotransferase; b.w., body weight; BSA, bovine serum albumin; CAT, catalase; CNCl, Chittaranjan National Cancer Institute; CPCSEA, Committee for the purpose of control and supervision of experiments on animals; CRIA, Central Research Institute of Ayurveda; DPPH, 2,2-diphenyl-1-picrylhydrazyl; EDTA, Ethylenediamine tetraacetic acid; ELISA, Enzyme-Linked Immunosorbent Assay; g, Gram; GSH, reduced glutathione; GST, glutathione-S-transferase; HPLC, high performance liquid chromatography; i.p, intraperitoneal; kg, kilogram; M, molar; MDA, malondialdehyde; mg, milligram; ml, milliliter; mM, millimolar; RNS, reactive nitrogen species; ROS, reactive oxygen species; SD, standard deviation; SOD, superoxide dismutase; TBARS, thiobarbituric reactive substances

\section{Acknowledgments}

The authors would like to acknowledge Mr. Ranjit K. Das and Mr. Pradip K. Mallick for their technical assistance.

\section{Funding}

This study was conducted with the financial support from Council of Scientific and Industrial Research (CSIR), Govt. of India [Grant No: 27(210)/09EMR-II Dated: 15.10.2009]. 


\section{Availability of data and materials}

The datasets supporting the conclusions of this article are included within the article.

\section{Authors' contributions}

Conceived and designed the experiments: NM. Performed the experiments: DC, NBG, SP. Analyzed the data: DC, TB, AKS. Contributed reagents/materials/ analysis tools: NM. Wrote the paper: DC, NBG, NM. It is also confirm that all the authors have read and approve of the manuscript.

\section{Competing interests}

The author(s) declare(s) that they have no competing interests.

\section{Consent for publication}

The manuscript does not contain any individual person's data in any form. So, this information is not relevant.

\section{Ethics approval and consent to participate}

Manuscript does not deal with the human participants, human data or human tissue. So, this information is not relevant. In vivo experiments were performed abiding by the guidelines of the Committee for the Purpose of Control and Supervision of Experiments on Animals (CPCSEA), Ministry of Environment and Forest, Govt. of India with due approval from the Institutional Animal Ethics Committee, Bose Institute (Registration. No. 95/1999/CPCSEA).

\section{Received: 27 February 2016 Accepted: 23 July 2016}

Published online: 29 July 2016

\section{References}

1. Maher JJ. Exploring alcohol's effects on liver function. Alcohol Health Res World. 1997;21:5-12.

2. Goodman LS, Gilman A. The Pharmacological Basis of Therapeutics. 11th ed. New York, NY, USA: McGraw-Hill; 2006.

3. Barton JC. Optimal management strategies for chroniciron overload. Drugs. 2007;67:685-700

4. Flora SJ. Structural, chemical and biological aspects of antioxidants for strategies against metal and metalloid exposure. Oxid Med Cell Longev. 2009;2:191-206.

5. Hazra B, Biswas S, Mandal N. Antioxidant and free radical scavenging activity of Spondias pinnata. BMC Complement Altern Med. 2008;8:63.

6. Hazra B, Sarkar R, Mandal N. Spondias pinnata stem bark extract lessens iron overloaded liver toxicity due to hemosiderosis in Swiss albino mice. Ann Hepatol. 2013:12:123-9.

7. Sarkar R, Hazra B, Mandal N. Reducing power and iron chelating property of Terminalia chebula (Retz.) alleviates iron induced liver toxicity in mice. BMC Complement Altern Med. 2012;12:144

8. Harborne JB, Baxter H. Phytochemical dictionary: a handbook of bioactive compounds from plants. 4 John St. London: Taylor \& Francis Ltd.; 1995.

9. Kokate CK, Purohit AP, Gokhale SB. Test book of Pharmacognosy. Pune: Nirali Prakashan; 2003.

10. Ghate NB, Chaudhuri D, Sarkar R, Sajem AL, Panja S, Rout J, Mandal N. An antioxidant extract of tropical lichen, Parmotrema reticulatum, induces cell cycle arrest and apoptosis in breast carcinoma cell line MCF-7. PLoS One. 2013:8:e82293.

11. Bonkovsky HL. Iron and the liver. Am J Med Sci. 1991;301:32-43.

12. Kell DB. Towards a unifying, systems biology understanding of large-scale cellular death and destruction caused by poorly liganded iron: Parkinson's, Huntington's, Alzheimer's, prions, bactericides, chemical toxicology and others as examples. Arch Toxicol. 2010;84:825-89.

13. Stief TW. The physiology and pharmacology of single oxygen. Med Hypotheses. 2003;60:567-72.

14. Halliwell B. Reactive oxygen species in living systems: source, biochemistry, and role in human disease. Am J Med. 1991:9:14S-22S.

15. Huie RE, Padmaja S. The reaction of NO with superoxide. Free Radic Res Commun. 1993:18:195-9.

16. Ghate NB, Chaudhuri D, Das A, Panja S, Mandal N. An antioxidant extract of the insectivorous plant Drosera burmannii vahl. alleviates iron-induced oxidative stress and hepatic injury in mice. PLoS One. 2015;10:e0128221.

17. Cheong JW, Kim HJ, Lee KH, Yoon SS, Lee JH, Park HS, Kim HY, Shim H, Seong CM, Kim CS, Chung J, Hyun MS, Jo DY, Jung CW, Sohn SK, Yoon HJ,
Kim BS, Joo YD, Park CY, Min YH. Deferasirox improves hematologic and hepatic function with effective reduction of serum ferritin and liver iron concentration in transfusional iron overload patients with myelodysplastic syndrome or aplastic anemia. Transfusion. 2014;54:1542-51.

18. Zuyderhoudt FM, Sindram JW, Marx JJ, Jörning GG, Van Gool J. The amount of ferritin and hemosiderin in the livers of patients with iron-loading diseases. Hepatology. 1983;3:232-5.

19. Harrison PM. Ferritin: an iron-storage molecule. Semin Hematol. 1977;14:55-70.

20. Liu T, Wang X, Karsdal MA, Leeming DJ, Genovese F. Molecular serum markers of liver fibrosis. Biomark Insights. 2012;7:105-17.

21. Kocabay G, Telci A, Tutuncu Y, Tiryaki B, Ozel S, Cevikbas U, Okten A, Satman I. Alkaline phosphatase: can it be considered as an indicator of liver fibrosis in nonalcoholic steatohepatitis with type 2 diabetes? Bratisl Lek Listy. 2011;112:626-9.

22. Pulla Reddy A, Lokesh BR. Effect of curcumin and eugenol on iron-induced hepatic toxicities in rats. Toxicol. 1996;107:39-45.

23. Thabrew M, Joice P. A comparative study of the efficacy of Pavetta indica and Osbeckia octanda in the treatment of liver dysfunction. Planta Med. 1987;53:239-41.

24. Sabir SM, Ahmad SD, Hamid A, Khand MQ, Athaydeb ML, Santosa DB Boligonb AA, Rocha JBT. Antioxidant and hepatoprotective activity of ethanolic extract of leaves of Solidago microglossa containing polyphenolic compounds. Food Chem. 2012;131:741-7.

25. Lee KS, Buck M, Houglum K, Chojkier M. Activation of hepatic stellate cells by TGF alpha and collagen type I is mediated by oxidative stress through cmyb expression. J Clin Invest. 1995:96:2461-8.

26. Farinati F, Cardin R, De Maria N, Della Libera G, Marafin C, Lecis E, Burra P, Floreani A, Cecchetto A, Naccarato R. Iron storage, lipid peroxidation and glutathione turnover in chronic anti HCV positive hepatitis. J Hepatol. 1995;22:449-56

27. Reeves HL, Burt AD, Wood S, Day CP. Hepatic stellate cell activation occurs in the absence of hepatitis in alcoholic liver disease and correlates with the severity of steatosis. J Hepatol. 1996:25:677-83.

28. Plebani M, Burlina A. Biochemical markers of hepatic fibrosis. Clin Biochem. 1991:24:219-39.

29. Dalle-Donne I, Rossi R, Giustarini D, Milzani A, Colombo R. Protein carbonyl groups as a biomarkers of oxidative stress. Clin Chim Acta. 2003:329:23-8.

30. Rice-Evans CA, Miller NJ, Bolwell PG, Bramley PM, Pridham JB. The relative antioxidant activities of plant-derived polyphenolic flavonoids. Free Radical Res. 1995;22:375-83.

31. Khatri A, Garg A, Agrawal SS. Evaluation of hepatoprotective activity of aerial parts of Tephrosia purpurea L. and stem bark of Tecomella undulate. J Ethnopharmacol. 2009;122:1-5.

32. Janbaz KH, Saeed SA, Gilani AH. Protective effect of rutin on paracetamoland $\mathrm{CCl}_{4}$-induced hepatotoxicity in rodents. Fitoterapia. 2002;73:557-63.

\section{Submit your next manuscript to BioMed Central and we will help you at every step:}

- We accept pre-submission inquiries

- Our selector tool helps you to find the most relevant journal

- We provide round the clock customer support

- Convenient online submission

- Thorough peer review

- Inclusion in PubMed and all major indexing services

- Maximum visibility for your research

Submit your manuscript at www.biomedcentral.com/submit 